\title{
Exercise testing in mitral valve prolapse before and after beta blockade
}

\author{
EDWARD G ABINADER, JULIO SHAHAR \\ From the Heart Institute and Intensive Coronary Care Unit, Rothschild University Hospital, Medical Faculty, \\ Technion, Haifa, Israel
}

SUMMARY Exercise electrocardiograms must be interpreted with the understanding that not every positive test is indicative of coronary artery disease. Mitral valve prolapse mimics coronary heart disease clinically and often in the electrocardiographic response to exercise. Twelve patients with mitral valve prolapse in whom exercise testing was positive underwent a repeat study after beta blockade. All tracings returned to normal after adequate blockade, evidenced by 17 to $22 \%$ reduction of resting and exercise heart rates. To the best of our knowledge, this is the first such report in the English literature.

The results of this study suggest that an exercise test after beta blockade should become part of the routine procedure in such patients. The elimination of false positive electrocardiographic responses by beta blockade should help improve the specificity of the exercise test. Moreover, similar responses should lead to the suspicion of mitral valve prolapse.

The resting electrocardiogram is a poor predictor of coronary disease, and the value of exercise testing in detecting myocardial ischaemia remains controversial. ${ }^{1}$ Exercise tests must be interpreted with the understanding that not every positive test is indicative of coronary artery disease.

Mitral valve prolapse is a common entity, many of whose features mimic those of coronary artery disease. Resting and exercise-induced electrocardiographic abnormalities in repolarisation in patients with mitral valve prolapse compound further the problem of differentiation.

One of us has studied the effect of beta blockade on the resting electrocardiogram in mitral valve prolapse ${ }^{2}$ and suggested that these changes may be due to the result of sympathetic overactivity. As exercise testing in mitral valve prolapse often induces changes in repolarisation, which mimic coronary heart disease, it seemed appropriate to investigate the effect of beta blockade on the electrocardiographic response to exercise in these patients.

Subjects and methods

Thirty-eight patients with mitral valve prolapse underwent exercise testing. Twelve (31.6\%) of these patients, nine women and three men, had a positive test. Their average age was 42 , with a range of 24 to 55 years. All patients had clinical and echocardiographic evidence of mitral valve prolapse. Those revealing pathological ST changes on exercise testing were included in this study, and none showed significant coronary disease on angiography. None had any evidence of coronary heart disease, cardiac failure, bronchial asthma, or bundle-branch block. All patients had their electrocardiograms recorded in the fasting state, having stopped all drugs in the preceding week.

A Hewlett Packard 1500 B electrocardiogram was I used at a paper speed of $25 \mathrm{~mm}$ per second and standardised to give a deflection of $10 \mathrm{~mm}$ for $1 \mathrm{mV}$. N Symptom-limited exercise testing was performed in the usual manner registering leads III and V5 every minute during exercise and the 10 minute recovery $\omega$ period, using bicycle ergometry (Elema Schonander A-B). Blood pressure was recorded before and during $\mathscr{C}$ the exercise test and in the recovery period. The first $\stackrel{\Phi}{\Phi}$ test was performed before and the second repeated one hour after $40 \mathrm{mg}$ oral propanolol in patients who had had a previously positive test. The criteria for a $\underset{\mathbb{D}}{\stackrel{D}{ }}$ positive exercise test were the development of ST $?$ segment depression $>1 \mathrm{~mm}$ and lasting $80 \mathrm{~ms}$ or $\varrho$ more. 
Table Symptoms and findings at rest and during exercise before and after beta blockade

\begin{tabular}{|c|c|c|c|c|c|c|c|}
\hline $\begin{array}{l}\text { Case } \\
\text { No. }\end{array}$ & $\begin{array}{l}\text { Age } \\
(y)\end{array}$ & Sex & Symptoms & Chest pain & $\begin{array}{l}\text { Resting } \\
\text { electrocardiogram }\end{array}$ & $\begin{array}{l}\text { Exercise electrocardiogram } \\
\text { before beta blockade }\end{array}$ & $\begin{array}{l}\text { Exercise electrocardiogram } \\
\text { after beta blockade } \star \star\end{array}$ \\
\hline 1 & 34 & $\mathbf{F}$ & - & - & HR $77 /$ min & $\underset{V E}{H R} 172 / \min$ & HR $140 / \mathrm{min}$ \\
\hline 2 & 52 & $\mathbf{M}$ & - & Atypical & $\begin{array}{l}\text { HR } 68 / \text { min } \\
\text { T } \downarrow \text { III, flat } T \text { aVF }\end{array}$ & HR $164 / \mathrm{min}$ & HR $105 / \mathrm{min}$ \\
\hline 3 & 35 & $\mathbf{F}$ & - & - & $\begin{array}{l}\text { HR } 77 / \mathrm{min} \\
\text { T」 III }\end{array}$ & HR $160 / \mathrm{min}$ & HR $128 / \min$ \\
\hline 4 & 55 & $\mathbf{F}$ & Palpitation & Atypical & $\begin{array}{l}\text { HR } 90 / \mathrm{min} \\
\text { T } \downarrow \text { III, V5, } \\
\text { flat T aVF }\end{array}$ & HR $164 / \min$ & HR $130 / \mathrm{min}$ \\
\hline 5 & 38 & $\mathbf{M}$ & Palpitation & - & HR $95 / \mathrm{min}$ & $\begin{array}{l}\text { HR } 170 / \mathrm{min} \\
\text { VE }\end{array}$ & $\begin{array}{l}\text { HR } 150 / \min \\
V E\end{array}$ \\
\hline $\begin{array}{l}6 \\
7\end{array}$ & $\begin{array}{l}33 \\
49\end{array}$ & $\begin{array}{l}\mathbf{F} \\
\mathbf{F}\end{array}$ & $\begin{array}{l}\text { Dyspnoea } \\
\text { Dyspnoea }\end{array}$ & $\overline{\text { Atypical }}$ & $\begin{array}{l}\text { HR } 95 / \mathrm{min} \\
\text { HR } 82 / \mathrm{min},\end{array}$ & $\begin{array}{l}\text { HR } 166 / \min \\
\text { HR } 164 / \mathrm{min}\end{array}$ & $\begin{array}{l}\text { HR } 123 / \mathrm{min} \\
\text { HR } 126 / \mathrm{min}\end{array}$ \\
\hline & & & & & $\begin{array}{l}\text { flat T V1-V4 } \\
\text { T } \downarrow \text { V5, V6 }\end{array}$ & & \\
\hline 8 & 54 & $\mathbf{M}$ & - & - & $\begin{array}{l}\text { HR } 80 / \mathrm{min} \\
\text { T\ III, aVF }\end{array}$ & HR $164 / \min$ & HR $127 / \mathrm{min}$ \\
\hline 9 & 46 & $\mathbf{F}$ & Palpitation & Atypical & $\begin{array}{l}\text { HR } 82 / \mathrm{min} \\
\text { T } \downarrow \text { III }\end{array}$ & $\begin{array}{l}\text { HR } 170 / \mathrm{min} \\
\mathrm{VE}\end{array}$ & HR $136 / \mathrm{min}$ \\
\hline 10 & 24 & $\mathbf{F}$ & Palpitation, & - & HR $100 / \mathrm{min}$ & HR $180 / \mathrm{min}$ & HR $148 / \min$ \\
\hline 11 & 48 & F & - $^{\text {ayspnoed }}$ & - & $\begin{array}{l}\text { HR } 77 / \mathrm{min}, \\
\text { flat T III, aVF }\end{array}$ & $\begin{array}{l}\text { HR } 158 / \mathrm{min} \\
\mathrm{VE}\end{array}$ & HR $133 / \min$ \\
\hline 12 & 36 & $\mathbf{F}$ & Palpitation & - & $\begin{array}{l}\text { HR } 84 / \mathrm{min} \\
\mathrm{T} \downarrow \text { III, VE }\end{array}$ & $\begin{array}{l}\text { HR } 166 / \mathrm{min} \\
\text { VE }\end{array}$ & $\begin{array}{l}\text { HR } 124 / \mathrm{min} \\
\text { VE }\end{array}$ \\
\hline
\end{tabular}

*All patients revealed pathological ST depression.

$\star \star$ None developed ST depression.

VE, ventricular extrasystoles; HR, heart rate.

\section{Results}

The Table refers to clinical and electrocardiographic findings at rest and exercise. Nine of the 12 patients (75\%) had minor $\mathrm{T}$ wave changes predominantly in leads III and aVF. None had resting ST depression. Five patients (41.6\%) experienced atypical chest pain during exercise, four (33.3\%) complained of dyspnoea, and seven (58.3\%) had palpitation. Beta blockers alleviated chest pain in two patients, dyspnoea in one, and palpitation in three. Five patients had ventricular extrasystoles during exercise when un-beta blocked which persisted in two patients after beta blockade. Changes were more prominent on exercise in lead V5. Beta blockade had no significant effect on blood pressure.

Analysis of the pattern of ST depression during exercise without beta blockade showed the following: five $(41.6 \%)$ developed electrocardiographic abnormalities during early exercise; nine $(75 \%)$ showed ST changes during the middle of exercise; five $(41.6 \%)$ showed abnormalities during peak exercise but none originating at this stage; five $(41.6 \%)$ had abnormalities in the early recovery phase but only in two patients $(16.6 \%)$ did these changes appear initially at this stage.

Before beta blockade the average resting heart rate was 83.9 beats/min (range: 68 to 100 beats $/ \mathrm{min}$ ); on exercise the average peak rate reached 166.5 beats/min (range: 158 to 180 beats/min). One hour after pro- pranolol the average resting heart rate was 69.4 beats/min (range: 52 to 82 beats $/ \mathrm{min}$ ), $82.7 \%$ of that before beta blockade. The peak exercise rate was now 130 beats/min (range: 105 to 150 beats $/ \mathrm{min}$ ), $78 \%$ of that before beta blockade. All tracings returned to normal (Fig. 1 and 2) when the exercise test was repeated one hour after oral propranolol. Fig. $3 \mathrm{a}$ and $\mathrm{b}$ shows cardiograms from two patients in whom, even though the rate achieved after beta blockade was higher than that at which ST changes appeared before medication, the exercise electrocardiogram failed to disclose ST changes after propranolol.

\section{Discussion}

It has been suggested that ethical obligations if not psychological pressure may enforce the performance of coronary angiography on all asymptomatic individuals with exercise-induced ST segment depression. ${ }^{1}$ The pressure to undertake coronary angiography is even greater in patients with symptoms and an abnormal exercise test. Mitral valve prolapse is a disorder in which clinical features may mimic those of coronary heart disease and exercise tests are often positive. The prevalence of abnormal exercise tests varies from 10 to $60 \%^{3}$; the overall prevalence, however, is in the region of 33\%. ${ }^{4}$ The risk and high cost of coronary angiography make it unsuitable for general use. Thus, any method that improves the diagnostic accuracy of the electrocardiographic response 
Fig. 1 Lead V5 of an exercise electrocardiogram of a patient with mitral valve prolapse and anginal type chest pain.

Maximum

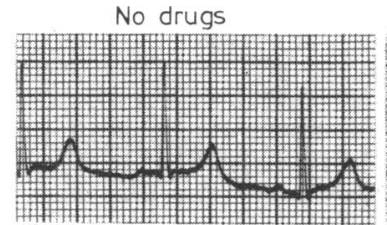

Propranolol

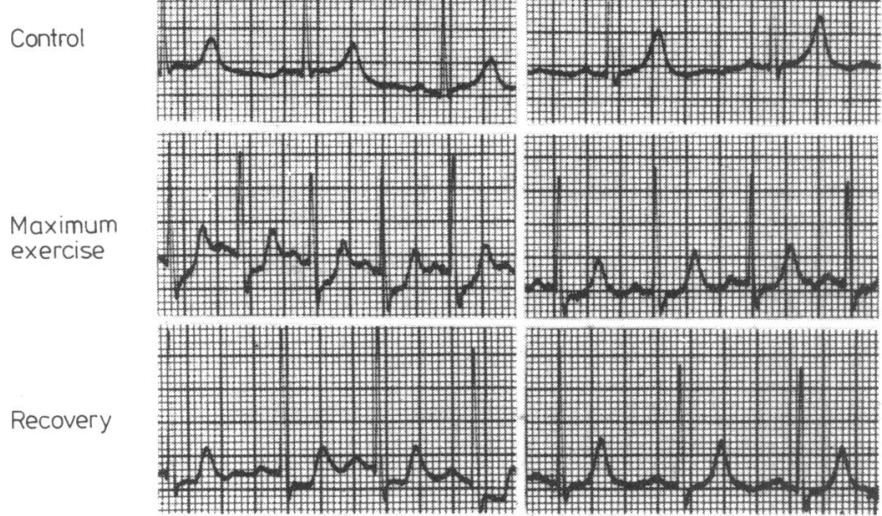

Left-positive before beta blockade.

Right-negative, one hour after $40 \mathrm{mg}$

propranolol. Coronary angiogram was normal.

Fig. 2 Lead V5 of an exercise electrocardiogram of a young woman with mitral valve prolapse and atypical chest discomfort. Left-rignificant $S T$ depression before propranolol. Right-normal ST segment one hour after $40 \mathrm{mg}$ propranolol.
Control
No drugs
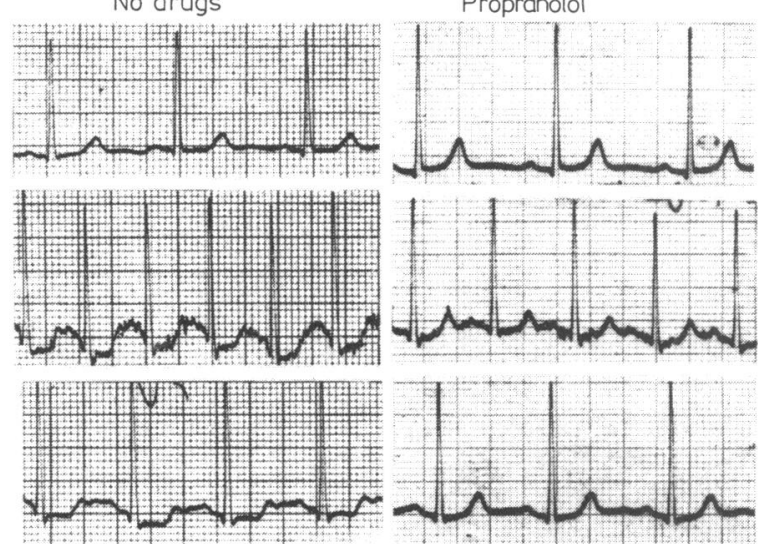

Maximum exercise \\ Recovery}

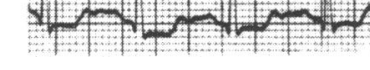

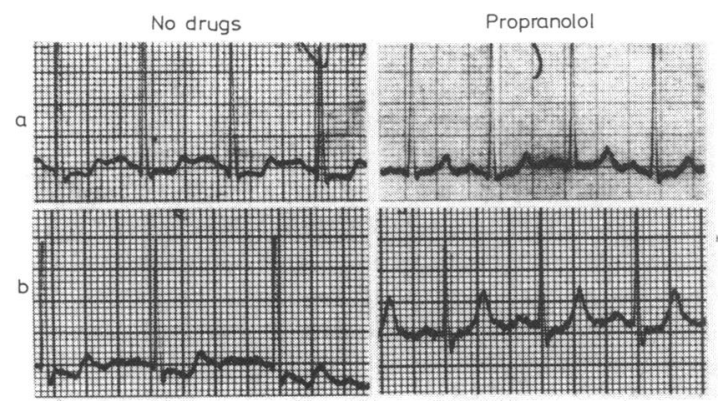

Fig. 3 Leads VS of an exercise electrocardiogram of two patients before and after propranolol. Note downsloping ST depression appearing (a) before propranolol at the rate of 109 min and (b) at $82 / \mathrm{min}$. After propranolol no ST depression was observed though the rate in (a) was 119 min and in (b) 100 min. 
to exercise will be valuable in the management of patients in general and those suffering from mitral valve prolapse in particular.

Following an attempt to elucidate the electrocardiographic findings in mitral valve prolapse by the effect of beta blockade on the resting electrocardiogram, ${ }^{2}$ sympathetic overactivity as the basis for these electrocardiographic abnormalities and other features related to mitral valve prolapse was studied and later confirmed by metabolic studies. ${ }^{5}$ The adequacy of beta blockade in the present study was confirmed by 17 to $22 \%$ reduction in resting and exercise heart rates. The exercise response of all patients returned to normal (Fig. 1 and 2). The pronounced "ischaemic" type ST depression appearing at exercise and during recovery returned to normal completely after beta blockade.

Thus our patients with mitral valve prolapse behaved similarly to the non-coronary group reported by Marcomichelakis et al., 6 in which 19 of 20 exercise tests returned to normal after beta blockade in patients none of whom had coronary heart disease or mitral valve prolapse. Exercise electrocardiograms after beta blockade, however, remained positive in 43 of their 44 patients with coronary artery disease; thus specificity and predictive value were improved without reduction in sensitivity. The chronotropic effect of propranolol does not seem to play a significant role as shown in Fig. 3. Two patients showed "ischaemic" ST depression before propranolol at a rate of 109 and 82 a minute, respectively. After propranolol these rates were surpassed, 119 and 100 a minute, respectively, and yet no ST changes appeared.

Twelve out of the 38 patients with mitral valve prolapse who performed an exercise test showed an abnormal result, a prevalence of $31.6 \%$. Though the contour of the ST segment depression was "ischaemic"-like, its behaviour differed from that seen in true ischaemia. Thus, $75 \%$ of the patients showed the abnormal response in the middle of the exercise period; the ST depression persisted through the peak exercise stage in only $41.6 \%$ of our patients and in none did it originate at this stage.

Our results are in keeping with the thesis that the ischaemic-like electrocardiographic abnormalities in mitral valve prolapse at rest ${ }^{2}$ and at exercise are not of coronary origin, but are a consequence of sympathetic overactivity and increased catecholamines or of altered myocardial sensitivity to these amines. Furthermore, exercise-induced electrocardiographic changes resembling those of ischaemia may be mimicked by adrenaline infusion and blocked by oxprenolol. ${ }^{7}$

If our observations are confirmed, the need for coronary angiography will be much reduced in symptomatic patients with mitral valve prolapse and positive exercise tests. We suggest that an exercise test after beta blockade should become part of the routine procedure in investigating such patients. Moreover, by eliminating false positive electrocardiographic responses in this group of patients, the specificity of exercise testing in the investigation of coronary heart disease will be improved.

\section{References}

1 Redwood DR, Borer JS, Epstein SE. Whither the ST segment during exercise? Circulation 1976; 54: 703-6.

2 Abinader EG. Adrenergic beta blockade and ECG changes in the systolic click murmur syndrome. Am Heart f 1976; 91: 297-302.

3 Devereux RB, Perloff JK, Reichek N, Josephson ME. Mitral valve prolapse. Circulation 1976; 54: 3-14.

4 Engel PJ, Alpert BL, Hichman JR. The nature and prevalence of the abnormal exercise electrocardiogram in mitral valve prolapse. Am Heart f 1979; 98: 716-24.

5 Boudoulas H, Reynolds JC, Mazzaferri E, Wooley CF. Metabolic studies in mitral valve prolapse syndrome. A neuroendocrine-cardiovascular process. Circulation 1980; 61: 1200-5.

6 Marcomichelakis J, Donaldson R, Green J, et al. Exercise testing after beta blockade: improved specificity and predictive value in detecting coronary heart disease. $\mathrm{Br} \mathrm{Heart}$ F 1980; 43: 252-61.

7 Taggart P, Carruthers M, Joseph S, et al. Electrocardiographic changes resembling myocardial ischaemia in asymptomatic men with normal coronary arteriograms. $\mathrm{Br}$ Heart f 1979; 41: 214-25.

Requests for reprints to: Dr Edward G Abinader, Heart Institute, Rothschild University Hospital, POB 4940, Haifa, Israel. 